\title{
Knockdown of TNF- $\alpha$ alleviates acute lung injury in rats with intestinal ischemia and reperfusion injury by upregulating IL-10 expression
}

\author{
ZHEN YANG $^{1,2^{*}}$, XUE-RONG ZHANG $^{3 *}$, QIONG ZHAO ${ }^{3}$, SHENG-LAN WANG ${ }^{1}$, LIU-LIN XIONG ${ }^{4}$, PIAO ZHANG ${ }^{2}$, \\ BING YUAN $^{1}$, ZI-BING ZHANG ${ }^{4}$, SHU-YUAN FAN ${ }^{1}$, TING-HUA WANG ${ }^{2,4^{* *}}$ and YUN-HUI ZHANG ${ }^{1 * *}$ \\ ${ }^{1}$ Department of Respiration, First People's Hospital of Yunnan Province, Kunming, Yunnan 650032; \\ ${ }^{2}$ Institute of Neuroscience, Kunming Medical University, Kunming, Yunnan 650500; ${ }^{3}$ Department of Anesthesiology, \\ Sun Yat-Sen Memorial Hospital, Sun Yat-Sen University, Guangzhou, Guangdong 510120; \\ ${ }^{4}$ Department of Anesthesiology and Institute of Neurological Disease, Translational Neuroscience Center, \\ West China Hospital, Sichuan University, Chengdu, Sichuan 610041, P.R. China
}

Received June 15, 2016; Accepted April 26, 2018

DOI: $10.3892 / \mathrm{ijmm} .2018 .3674$

\begin{abstract}
Intestinal ischemia and reperfusion (II/R) injury often triggers severe injury in remote organs, with the lungs being considered the main target. Excessive elevation of proinflammatory cytokines is a major contributor in the occurrence and development of II/R-induced acute lung injury (ALI). Therefore, the present study aimed to investigate whether blocking tumor necrosis factor- $\alpha$ (TNF- $\alpha$ ) expression could protect the lungs from injury following II/R, and to explore the possible underlying mechanism involving interleukin-10 (IL-10). Briefly, II/R was induced in rats by $40 \mathrm{~min}$ occlusion of the superior mesenteric artery and celiac artery, followed by 8,16 or $24 \mathrm{~h}$ of reperfusion. Subsequently, lentiviral vectors containing TNF- $\alpha$ short hairpin (sh)RNA were injected into the right lung tissues, in order to induce TNF- $\alpha$ knockdown. The severity of ALI was determined according to lung injury scores and lung edema (lung wet/dry weight ratio). The expression levels of TNF- $\alpha$ were analyzed by quantitative polymerase chain reaction (qPCR), western blotting and immunofluorescence (IF) staining. IL-10 expression, in response to TNF- $\alpha$ knockdown, was detected in lung tissues by qPCR and IF. The results detected marked inflammatory
\end{abstract}

Correspondence to: Professor Yun-Hui Zhang, Department of Respiration, First People's Hospital of Yunnan Province, 157 Jinbi Road, Kunming, Yunnan 650032, P.R. China

E-mail: yunhuizhang3188@126.com

Professor Ting-Hua Wang, Institute of Neuroscience, Kunming Medical University, 1168 Chunrong West Road, Yuhua Street, Kunming, Yunnan 650500, P.R. China

E-mail: tinghua_neuron@263.net

\section{${ }^{*, * *}$ Contributed equally}

Key words: tumor necrosis factor- $\alpha$, interleukin-10, RNA interference, intestinal ischemia and reperfusion, acute lung injury responses, and increased levels of lung wet/dry weight ratio and TNF- $\alpha$ expression, in the lungs of II/R rats. Conversely, treatment with TNF- $\alpha$ shRNA significantly alleviated the severity of ALI and upregulated the expression levels of IL-10 in lung tissues. These findings suggested that TNF- $\alpha$ RNA interference may exert a protective effect on II/R-induced ALI via the upregulation of IL-10. Therefore, TNF- $\alpha$ knockdown may be considered a potential strategy for the prevention or treatment of ALI induced by II/R in future clinical trials.

\section{Introduction}

Intestinal ischemia and reperfusion (II/R) is encountered under various clinical conditions, and contributes to multi-organ failure and high levels of mortality $(60-80 \%)(1-3)$. II/R not only induces intestinal damage, but also affects remote organs, including the lungs, leading to acute lung injury (ALI) and acute respiratory distress syndrome in patients $(4,5)$. II/R-induced ALI is caused by an excessive systemic inflammatory response, which is triggered by the release of proinflammatory cytokines and bacteria-derived endotoxins from the reperfused ischemic gut tissue (6-8). In addition, animal models and clinical data support the concept that excessive elevation of proinflammatory cytokines is a major contributor in remote organ injury following II/R (9-11).

Among the numerous proinflammatory cytokines, tumor necrosis factor- $\alpha$ (TNF- $\alpha$ ) has a critical role in the occurrence and development of ALI caused by II/R $(12,13)$. Preclinical and clinical studies have reported that suppressing the expression of TNF- $\alpha$ may reduce the progression of inflammation in numerous diseases, including Crohn's disease (14-16). Using an anti-TNF antibody, Caty et al revealed that blocking TNF ameliorates pulmonary microvascular permeability (13). In addition, Sorkine et al demonstrated that soluble TNF- $\alpha$ receptors have the ability to reduce bowel ischemia-induced lung permeability and neutrophil sequestration (17). These results suggest that $\mathrm{TNF}-\alpha$ may serve major roles in the lung injury induced by II/R. However, pharmaco- 
logical treatment options for ALI following II/R are limited, with most targeting proinflammatory cytokines and oxidative stress pathways (18). Therefore, there is an urgent requirement to identify an effective approach for ALI treatment.

Downregulation of mRNA transcripts by RNA interference (RNAi) and small interfering (si)RNA (19) has been adopted as an invaluable research tool, which holds promise as a novel strategy for drug development (14), via the suppression of targeted gene expression (20). As a therapeutic method, the RNAi approach is safe and has incomparable long-term effects.

It has been hypothesized that blocking expression of the proinflammatory cytokine TNF- $\alpha$ may protect the lungs from remote organ injury following II/R. Therefore, the present study employed a rat model of II/R injury and used short hairpin (sh)RNA technology to examine the efficacy of TNF- $\alpha$ knockdown on II/R-induced ALI, and to investigate its association with interleukin-10 (IL-10) expression in lung tissues.

\section{Materials and methods}

Animals and grouping. Adult male Sprague-Dawley rats (8-12 weeks old), weighing 230-280 g, were obtained from the Experimental Animal Center of Sichuan University (Chengdu, China). Guidelines for Laboratory Animal Care and Safety from the National Institutes of Health (Bethesda, MD, USA) were followed. The rats were maintained in plastic cages ( 2 rats/cage) with soft bedding, and were given free access to food and water. Rats were maintained under the following conditions: Controlled room temperature, $22-25^{\circ} \mathrm{C}$; humidity, 45-50\%; 12-h light/dark cycle. Animal care and all experimental protocols were approved by the Institutional Medical Experimental Animal Care Committee of Kunming Medical University (Kunming, China).

A total of 152 rats were randomly divided into the following two groups, as described in Table I: i) Sham and ii) II/R (8, 16 and $24 \mathrm{~h}$ ). In the II/R group, rats underwent II/R injury via occlusion of the superior mesenteric artery (SMA) and coeliac artery (CA) for $40 \mathrm{~min}$, and subsequent reperfusion for 8,16 or $24 \mathrm{~h}$. In addition, the II/R group was subdivided into the negative control (II/R $+\mathrm{Lv}-\mathrm{NC}$ vector) and TNF- $\alpha$ shRNA groups (II/R + RSH054951-5-HIVmU6), as described in Table II. Rats in the negative control group were injected with the Lv-NC vector, whereas rats in the TNF- $\alpha$ shRNA group were injected with the TNF- $\alpha$ shRNA lentivirus.

Production of lentivirus TNF- $\alpha$ shRNA plasmid. To investigate the function of TNF- $\alpha$ in rat lungs following II/R, human immunodeficiency virus (HIV)-based vectors were used. TNF- $\alpha$ gene information was gathered from the National Center for Biotechnology Information (https://www.ncbi. nlm.nih.gov/nuccore/NM_012675.3). One potential shRNA sequence targeting TNF- $\alpha$ mRNA (gccegtagcccacgtcgta) was used to silence TNF- $\alpha$ expression (called RSH0549515-HIVmU6; provided by GeneCopoeia, Inc., Rockville, MD, USA), whereas one non-sense shRNA sequence was used as a negative control; sequences were designed and purchased from GeneCopoeia, Inc.

RNA knockdown efficiency screening. In order to screen the efficiency of the potential TNF- $\alpha$ shRNA sequence,
Table I. Animal model and number of rats distribution.

\begin{tabular}{clcccc}
\hline Group & Model & $\begin{array}{c}\text { Lung } \\
\text { edema }\end{array}$ & H\&E & IF & qPCR/WB \\
\hline Sham & Sham & 8 & 6 & 6 & 8 \\
$8 \mathrm{~h}$ & II/R & 8 & 6 & 6 & 8 \\
$16 \mathrm{~h}$ & II/R & 8 & 6 & 6 & 8 \\
$24 \mathrm{~h}$ & II/R & 8 & 6 & 6 & 8 \\
\hline
\end{tabular}

H\&E, hematoxylin and eosin; IF, immunofluorescence; II/R, intestinal ischemia and reperfusion; qPCR, quantitative polymerase chain reaction; WB, western blotting.

Table II. Animal grouping and and number of rats distribution.

\begin{tabular}{llccc}
\hline Group & \multicolumn{1}{c}{ Model (24 h) } & H\&E & qPCR/WB & IF \\
\hline Control & II/R+Lv-NC vector & 6 & 8 & 6 \\
TNF- $\alpha$ shRNA & II/R+RSH054951-5- & 6 & 8 & 6 \\
& HIVmU6 & & & \\
\end{tabular}

H\&E, hematoxylin and eosin; IF, immunofluorescence; qPCR, quantitative polymerase chain reaction; shRNA, short hairpin RNA: TNF- $\alpha$, tumor necrosis factor- $\alpha$; WB, western blotting.

PC12 cells, purchased from the Animal Research Institute of the Chinese Academy of Medical Sciences (Beijing, China), were seeded in 6-well plates and incubated at $37^{\circ} \mathrm{C}$ in an atmosphere containing $5 \% \mathrm{CO}_{2}$, prior to transfection with shRNA sequences. Briefly, cultured PC12 cells $\left(1 \times 10^{5} / \mathrm{ml}\right)$, were transfected at $4^{\circ} \mathrm{C}$ with a mixture including $1 \mu \mathrm{g}$ shRNA fragment and $3 \mu \mathrm{l}$ transfection reagents (SuperFectin ${ }^{\mathrm{TM}}$ II; Shanghai Pufei Biological Technology Co., Ltd., Shanghai, China) according to the manufacturer's protocol. A total of $12 \mathrm{~h}$ post-transfection, basal culture medium was replaced with Dulbecco's modified Eagle's medium (DMEM; HyClone; GE Healthcare, Logan, UT, USA) containing 10\% fetal bovine serum (FBS; Gibco; Thermo Fisher Scientific, Inc., Waltham, MA, USA) and penicillin-streptomycin solution $(50 \mathrm{U} / \mathrm{ml}$; HyClone; GE Healthcare). Subsequently, total RNA was extracted from $\mathrm{PC} 12$ cells 48 h post-transfection and the effects of shRNA on TNF- $\alpha$ mRNA expression were examined using quantitative polymerase chain reaction (qPCR) (21). The protein expression levels were evaluated by western blotting.

Recombinant lentiviral vector production. Lentiviral vector production was conducted according to the manufacturer's protocol of the Lenti-Pac ${ }^{\mathrm{TM}}$ HIV Expression Packaging kit (GeneCopoeia, Inc.). Briefly, 293Ta lentiviral packaging cells (GeneCopoeia, Inc.) were cultured in DMEM supplemented with $10 \%$ heat-inactivated FBS at $37^{\circ} \mathrm{C}$ in an atmosphere containing $5 \% \mathrm{CO}_{2}$. Cell confluence between 70 and $80 \%$ was optimal for transfection. Lentiviral expression plasmid $(1.25 \mu \mathrm{g})$ was mixed with $2.5 \mu \mathrm{l}(0.5 \mu \mathrm{g} / \mu \mathrm{l})$ packing mix (Lenti-Pac HIV) and the mixture was added to $75 \mu \mathrm{l}$ Opti-MEM ${ }^{\circledR}$ I (Gibco; Thermo Fisher Scientific, Inc.). Diluted EndoFectin Lenti was also added to the vector mixture. 
Following incubation at room temperature for $25 \mathrm{~min}$, the mixtures were added to the culture medium of 293T $\alpha$ cells. Subsequently, $8 \mathrm{~h}$ post-transfection, the culture medium was replaced with heated DMEM containing 10\% FBS. Furthermore, Titer Boost reagent (10 $\mu \mathrm{l}$; GeneCopoeia, Inc.) was added to improve virus generation. Transfection efficiency was confirmed by the detection of mCherryFP, which was fused to the plasmid vector, under a fluorescence microscope. A total of $72 \mathrm{~h}$ post-transfection, cells were stimulated, the culture medium was collected and centrifuged at $3,600 \mathrm{x} \mathrm{g}$ for $10 \mathrm{~min}$ at $4^{\circ} \mathrm{C}$, and the supernatant was filtered. Lentiviral stocks were aliquoted and stored at $-80^{\circ} \mathrm{C}$ until further use (21).

$I I / R$ model and lentivirus injection. Rats were fasted with no restriction of water access for $24 \mathrm{~h}$ prior to surgery. II/R was induced by SMA and CA occlusion, as described previously (22). Briefly, the rats were anesthetized intraperitoneally (i.p.) with ketamine-xylazine (100 and $20 \mathrm{mg} / \mathrm{kg}$ i.p., respectively) and placed in a supine position. The SMA and CA were exposed and isolated through a midline laparotomy and clamped with an atraumatic microvascular clip for $40 \mathrm{~min}$. After $40 \mathrm{~min}$ ischemia, the artery clamps were removed and intestinal perfusion was re-established. Sham animals underwent the same surgical procedure without artery clamping.

For TNF- $\alpha$ interference, the previously described lentiviruses were injected through the diaphragm into the right lung tissue $\left(5 \mu \mathrm{l} / 2 \times 10^{8} / \mathrm{ml}\right)$. After $3 \mathrm{~min}$, the needle tip was pulled out and the diaphragm was sutured. The arteries were clamped following lentiviral injection. After $40 \mathrm{~min}$ of ischemia, the SMA and CA were loosened and the skin was sutured, after which $0.5 \mathrm{ml}$ normal saline was injected into the enterocoelia. Rats in the negative control group were injected with Lv-NC.

Tissue harvest. At the end of reperfusion (8, 16 and $24 \mathrm{~h}$ ), experimental and sham rats were anaesthetized with ketamine-xylazine (100 and $20 \mathrm{mg} / \mathrm{kg}$ i.p., respectively) and euthanized with pentobarbital sodium $(200 \mathrm{mg} / \mathrm{kg}$ i.p.). Subsequently, lung tissues from rats in each group were collected and analyzed.

Lung edema determination. Lung edema was estimated by comparing the lung wet/dry weight ratio. At the end of the experiments, lungs were immediately removed and weighed to obtain the wet weight. The tissues were then dried in an oven at $90^{\circ} \mathrm{C}$ for $24 \mathrm{~h}$ and were weighed again to obtain the dry weight. Lung wet/dry weight ratio was calculated as previously described (23).

Histological analysis. Histological analysis of the lungs was performed by hematoxylin and eosin (H\&E) staining. Briefly, tissue samples were fixed in $10 \%(\mathrm{v} / \mathrm{v})$ formalin in neutral-buffered solution for $72 \mathrm{~h}$ at room temprature, and the fixed tissues were embedded in paraffin. Subsequently, tissue blocks were cut into 5- $\mu \mathrm{m}$ sections, transferred to glass slides and stained with hematoxylin for $7 \mathrm{~min}$, and eosin for $15 \mathrm{sec}$ respectively, at room temprature. Finally, these sections were observed under a light microscope to detect morphological alterations. Lung injury was scored as previously described (24).

Reverse transcription $(R T)$ - $q P C R$. The mRNA expression levels of TNF- $\alpha$ and IL-10 were detected using RT-qPCR.
Briefly, total RNA was isolated from the lung tissues using TRIzol $^{\circledR}$ reagent (Invitrogen; Thermo Fisher Scientific, Inc.), according to the manufacturer's protocol. RNA was reverse transcribed to cDNA using the RevertAid ${ }^{\mathrm{TM}}$ First Strand cDNA Synthesis kit (Thermo Fisher Scientific, Inc.) according to the manufacturer's protocol. qPCR was then performed to determine the expression levels of target genes. The primers and TaqMan probes were designed with Primer Premier 5.0 (Premier Biosoft International, Palo Alto, CA, USA). The primer sequences were as follows (5'-3'): TNF- $\alpha$, forward GCC CACGTCGTAGCAA, reverse, GTCTTTGAGATCCATGCC AT (annealing temperature, $52^{\circ} \mathrm{C}$ ); IL-10, forward CAGAAA TCAAGGAGCATTTG, reverse CTGCTCCACTGCCTTGCT TT (annealing temperature, $50^{\circ} \mathrm{C}$ ); and $\beta$-actin, forward GAA GATCAAGATCAT TGCTCCT and reverse TACTCCTGC TTGCTGATCCA (annealing temperature, $52^{\circ} \mathrm{C}$ ). The rat $\beta$-actin housekeeping gene was used as an internal control. The qPCR reactive system was established as follows: $2 X$ PCR, Master Mix (12.5 $\mu \mathrm{l})$, PCR water nuclear-free (10.5 $\mu \mathrm{l})$, forward primer $(0.5 \mu \mathrm{l})$, reverse prime $(0.5 \mu \mathrm{l})$, cDNA template $(1 \mu \mathrm{l})$; total, $25 \mu \mathrm{l}$; $1 \mu \mathrm{l}$ water was added as a negative control instead of cDNA. Amplification was conducted using an ABI 7300 PCR system (Applied Biosystems; Thermo Fisher Scientific, Inc.), under the following conditions: Initial denaturation for 1 cycle at $95^{\circ} \mathrm{C}$ for $2 \mathrm{~min}$, followed by denaturation at $95^{\circ} \mathrm{C}$ for $15 \mathrm{sec}$, and amplification at $53^{\circ} \mathrm{C}$ for $20 \mathrm{sec}$ and followed by extension at $60^{\circ} \mathrm{C}$ for $30 \mathrm{sec}$ for a total of 40 cycles. The quantification cycle $(\mathrm{Cq})$ of each sample was recorded as a quantitative measure of the amount of PCR product in the sample. Finally, the relative mRNA expression levels of the target genes were calculated following normalization to $\beta$-actin mRNA using the $2^{-\Delta \Delta \mathrm{Cq}}$ method (25).

Immunofluorescence (IF) staining. A total of 8,16 and $24 \mathrm{~h}$ following reperfusion, paraffin-embedded lung sections underwent IF staining of TNF- $\alpha$ and IL-10. Following routine de-paraffinization and rehydration, tissue sections were incubated with PBS containing 3\% goat serum (Sigma, St. Louis, MO, USA) for $30 \mathrm{~min}$ at $37^{\circ} \mathrm{C}$, and were then incubated overnight at $4^{\circ} \mathrm{C}$ with TNF- $\alpha$ (1:500, rabbit) and IL-10 (1:100, rabbit; catalog no. Ab9969) primary antibodies (both from Abcam, Cambridge, UK) which were diluted in PBS containing $2 \%$ normal goat serum. A negative control was performed by adding PBS instead of the primary antibody. Subsequently, sections were washed three times with PBS and were incubated with $\mathrm{Cy} 3$ fluorescence-labeled secondary antibody (1:200, anti-rabbit; catalog no. 111-165-003; Jackson Laboratory, Bar Harbor, ME, USA), in the dark for $30 \mathrm{~min}$ at $37^{\circ} \mathrm{C}$. Sections were then washed three times with PBS, mounted onto gelatin-coated glass microscope slides, air dried and cover-slipped in a glycerol-based mounting medium. Cell nuclei were visualized by DAPI-Fluoromount (Beyotime Institute of Biotechnology, Shanghai, China). Photomicrographs were captured under a fluorescence microscope (Leica Microsystems GmbH, Wetzlar, Germany).

Western blotting. Tissue samples were lysed and homogenized in $50 \mathrm{ml}$ radioimmunoprecipitation acid lysis buffer (Beyotime Institute of Biotechnology) containing a $2 \%$ protease inhibitor cocktail tablet (Roche Diagnostics GmbH,Mannheim, Germany). 

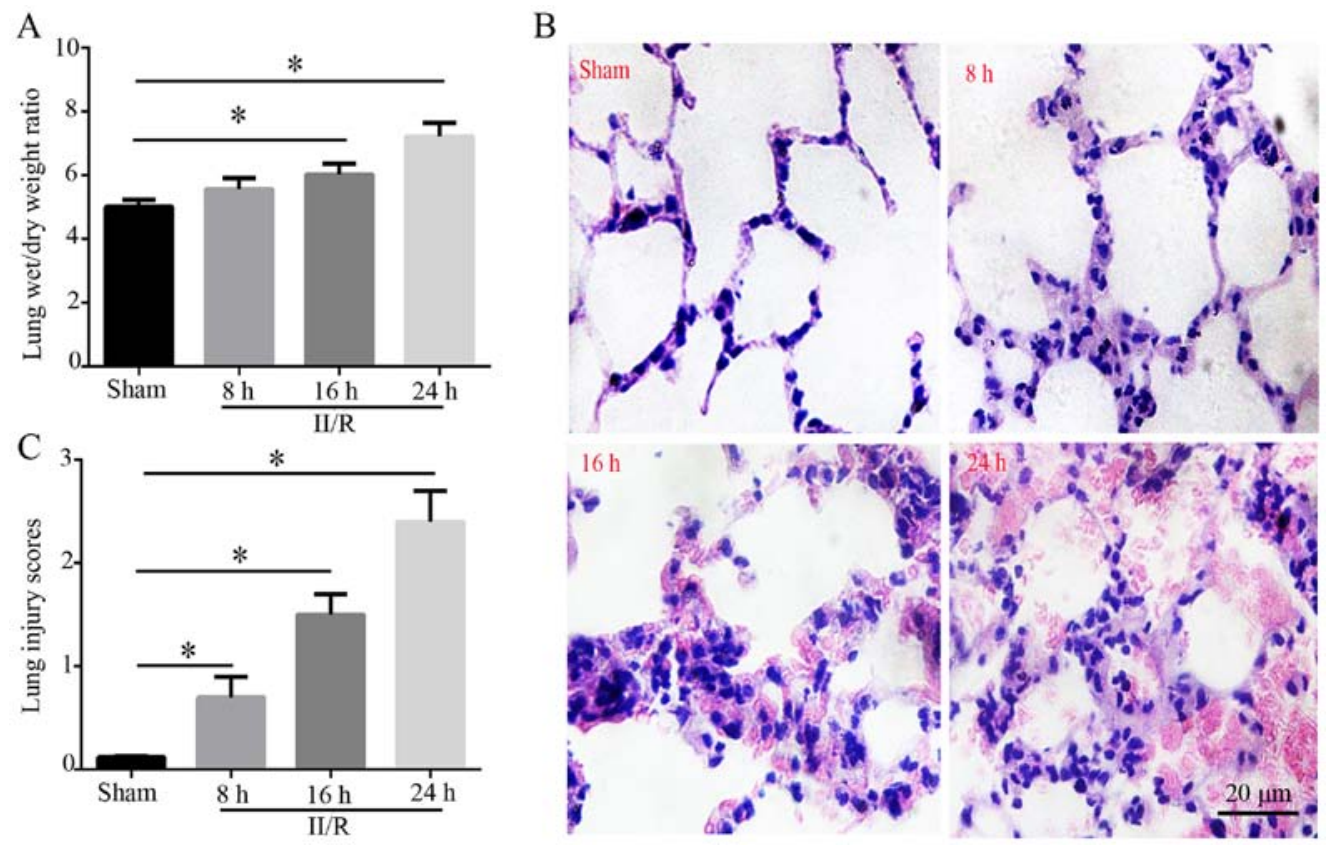

Figure 1. Lung edema and morphological damage are induced by II/R. (A) Lung edema was analyzed by lung wet/dry weight ratio in the sham and II/R groups $\left(8,16\right.$ and $24 \mathrm{~h}$ after reperfusion). Data are presented as the means \pm standard deviation $(\mathrm{n}=8)$. ${ }^{*} \mathrm{P}<0.05$ compared with the sham group. (B) Morphological alterations in the lung tissue of the sham and II/R groups (8, 16 and $24 \mathrm{~h})$ were observed under a light microscope. Disordered alveolar structure, congestion, neutrophil invasion and interstitial edema were observed in the lungs of the II/R group ( 8,16 and $24 \mathrm{~h})$. Scale bar, $20 \mu \mathrm{m}$. (C) Lung injury scores in the sham and II/R groups. Data are presented as the means \pm standard deviation $(n=6) .{ }^{*} \mathrm{P}<0.05$ compared with the sham group. II/R, intestinal ischemia and reperfusion.

Subsequently, a Bicinchoninic Acid protein assay kit (Beyotime Institute of Biotechnology) was used to detect the protein concentration and, $100 \mu \mathrm{g}$ total protein was then resolved by $15 \%$ SDS-PAGE in electrophoresis buffer (24.8 mM Tris, $192 \mathrm{mM}$ glycine and $0.1 \% \mathrm{SDS}$ ) at $60 \mathrm{~V}$ for $30 \mathrm{~min}$, and $100 \mathrm{~V}$ for $1.5 \mathrm{~h}$. The precipitated proteins were then transferred to polyvinylidene fluoride membranes (EMD Millipore, Billerica, MA, USA) at $350 \mathrm{~mA}$ for $4 \mathrm{~h}$, using transfer buffer: $24.8 \mathrm{mM}$ Tris, $192 \mathrm{mM}$ glycine and $10 \%$ methanol. The membranes were blocked with Tris-buffered saline with 1/1,000 Tween (TBST) containing $5 \%$ non-fat milk for $1 \mathrm{~h}$ at room temperature. Subsequently, the membranes were incubated with TNF- $\alpha$ primary antibody (1:5,000, rabbit anti-rat; ab9755; Abcam) in TBS overnight at $4^{\circ} \mathrm{C}$; $\beta$-actin (1:1,000; catalog no. ABM40028; Abcam) was used as an internal control. Following incubation with the primary antibodies, membranes were repeatedly rinsed in TBST four times prior to incubation for $1.5 \mathrm{~h}$ with a secondary antibody at room temprature (goat anti-rabbit immunoglobulin G; 1:5,000; catalog no. ab6721; Abcam). Finally, the membranes were rinsed four times in TBST and detected using ChemiDoc XRS System with Image Lab Software 2.0 (Bio-Rad Laboratories, Inc., Hercules, CA, USA) using an Enhanced Chemiluminescence reagent (catalog no. BL520A; Bio-Rad Laboratories, Inc.).

Statistical analysis. Statistical analysis was conducted using SPSS 18.0 software (SPSS, Inc., Chicago, IL, USA) and the experiments were repeated 3 times. Data are presented as the means \pm standard deviation and were subjected to statistical analysis using one-way analysis of variance (ANOVA) or Student's t-test. For multiple group comparisons, ANOVA with Tukey's post hoc multiple comparisons test was applied. $\mathrm{P}<0.05$ was considered to indicate a statistically significant difference.

\section{Results}

Lung edema and morphology. Compared with in the sham group, the lung wet/dry weight ratio of the II/R group was significantly increased 8, 16 and $24 \mathrm{~h}$ after reperfusion; the results indicated that pulmonary edema was aggravated as the time interval lengthened $(\mathrm{P}<0.05$; Fig. 1A). As shown in Fig. 1B, lung tissue sections were stained with $\mathrm{H} \& \mathrm{E}$ and observed under a light microscope; alveolar structure in the sham group was ordered, and no congestion, neutrophil invasion or interstitial edema was detected. However, in the II/R group, the alveolar structure was disordered and integrity of the alveolar wall was damaged, which was accompanied by a thickened alveolar wall and edema. In addition, neutrophils accumulated in the alveolar space, alveolar capillary congestion and exudation occurred, part of the alveolus pulmonis collapsed, and there was hemorrhaging in the alveolar space. Based on these observations, lung injury scores were significantly increased in the II/R group compared with in the sham group 8, 16 and 24 h post-reperfusion ( $\mathrm{P}<0.05$; Fig. 1C).

Expression levels of TNF- $\alpha$ in lung tissues. Between 8 and $24 \mathrm{~h}$ post-reperfusion, the mRNA and protein expression levels of TNF- $\alpha$ in the II/R group exhibited an increasing trend compared with in the sham group $(\mathrm{P}<0.05$; Fig. $2 \mathrm{~A}$ and $\mathrm{B})$. In addition, IF labeling of TNF- $\alpha$, which exhibited red fluorescence, indicated that weak TNF- $\alpha$ immunostaining was detected in the lung tissues of the sham group, whereas strong immunostaining was detected in the lung tissues of the II/R group 8, 16 and $24 \mathrm{~h}$ post-reperfusion. In particular, TNF- $\alpha$ immunostaining was diffuse and intense $24 \mathrm{~h}$ following reperfusion (Fig. 2C).

Efficiency of TNF- $\alpha$ knockdown. Lentivirus-mediated TNF- $\alpha$ interference was used to knockdown the expression of TNF- $\alpha$. 

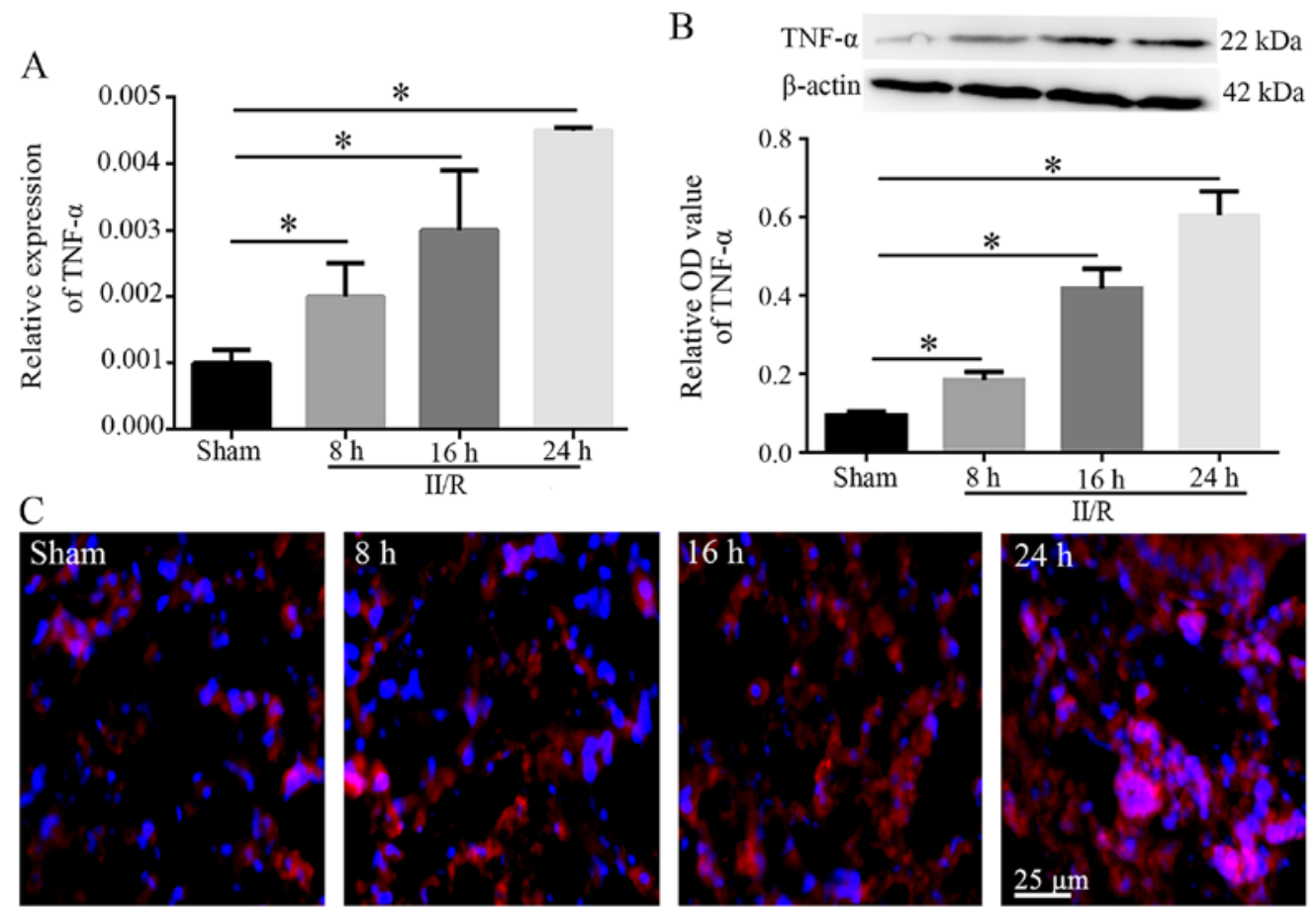

Figure 2. Expression levels of TNF- $\alpha$ in lung tissues. (A) mRNA expression levels of TNF- $\alpha$ were detected in lung tissues by quantitative polymerase chain reaction. Data are presented as the means \pm standard deviation $(\mathrm{n}=8)$. ${ }^{*} \mathrm{P}<0.05$ compared with the sham group. (B) Protein expression levels of TNF- $\alpha$ were assessed by western blotting. Compared with in the sham group, TNF- $\alpha$ protein expression was increased in the lung tissue 8,16 and $24 \mathrm{~h}$ post-reperfusion in the II/R group. Data are presented as the means \pm standard deviation $(n=8)$. ${ }^{*} \mathrm{P}<0.05$ compared with the sham group. (C) Representative photomicrographs exhibiting immunostaining of TNF- $\alpha$ (red fluorescence) in lung cells from the sham and II/R groups $(8,16$ and $24 \mathrm{~h}$ post-reperfusion). Immunofluorescence intensity was increased between the two groups; the $24 \mathrm{~h}$ post-reperfusion group possessed the strongest red staining. Blue fluorescence represented nuclei stained by DAPI. Scale bar, $25 \mu \mathrm{m}$. II/R, intestinal ischemia and reperfusion; OD, optical density; TNF- $\alpha$, tumor necrosis factor- $\alpha$.

A

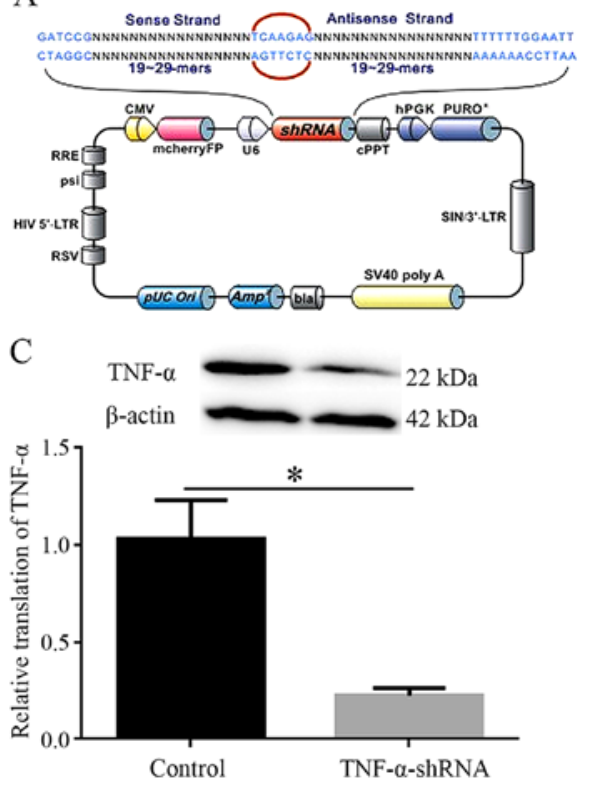

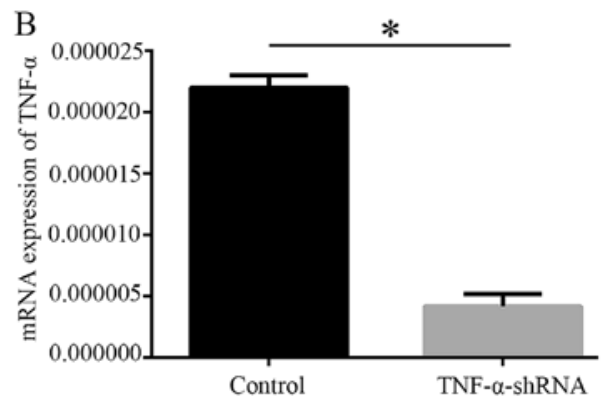

$\mathrm{D}$

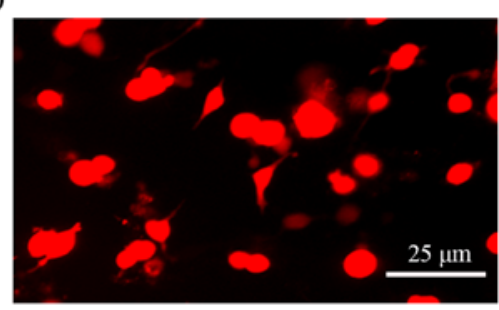

Figure 3. Generation of a recombinant lentivirus targeting TNF- $\alpha$. (A) TNF- $\alpha$ shRNA was inserted into a lentivirus plasmid; the sequence is stated. (B) mRNA expression levels of TNF- $\alpha$ were measured by quantitative polymerase chain reaction. (C) Protein expression levels of TNF- $\alpha$ were measured by western blotting. Data are presented as the means \pm standard deviation. $\mathrm{P}<0.05$ compared with the control group (non-sense shRNA). (D) 293T $\alpha$ cells were transfected with TNF- $\alpha$ shRNA lentivirus. Virus production carrying mCherryFP was visualized as red staining under a fluorescence microscope, indicating successful transfection. Scale bar, $25 \mu \mathrm{m}$. OD, optical density; shRNA, short hairpin RNA; TNF- $\alpha$, tumor necrosis factor- $\alpha$.

The lentivirus-carried TNF- $\alpha$ shRNA sequence is presented in Fig. 3A. PC12 cells were subjected to shRNA transfection, in order to determine the interfering efficiency. Compared with in the control group, the mRNA and protein expression levels of TNF- $\alpha$ were reduced in the shRNA plasmid transfection groups $(\mathrm{P}<0.05)$, as determined by $\mathrm{PPCR}$ and western blot- 


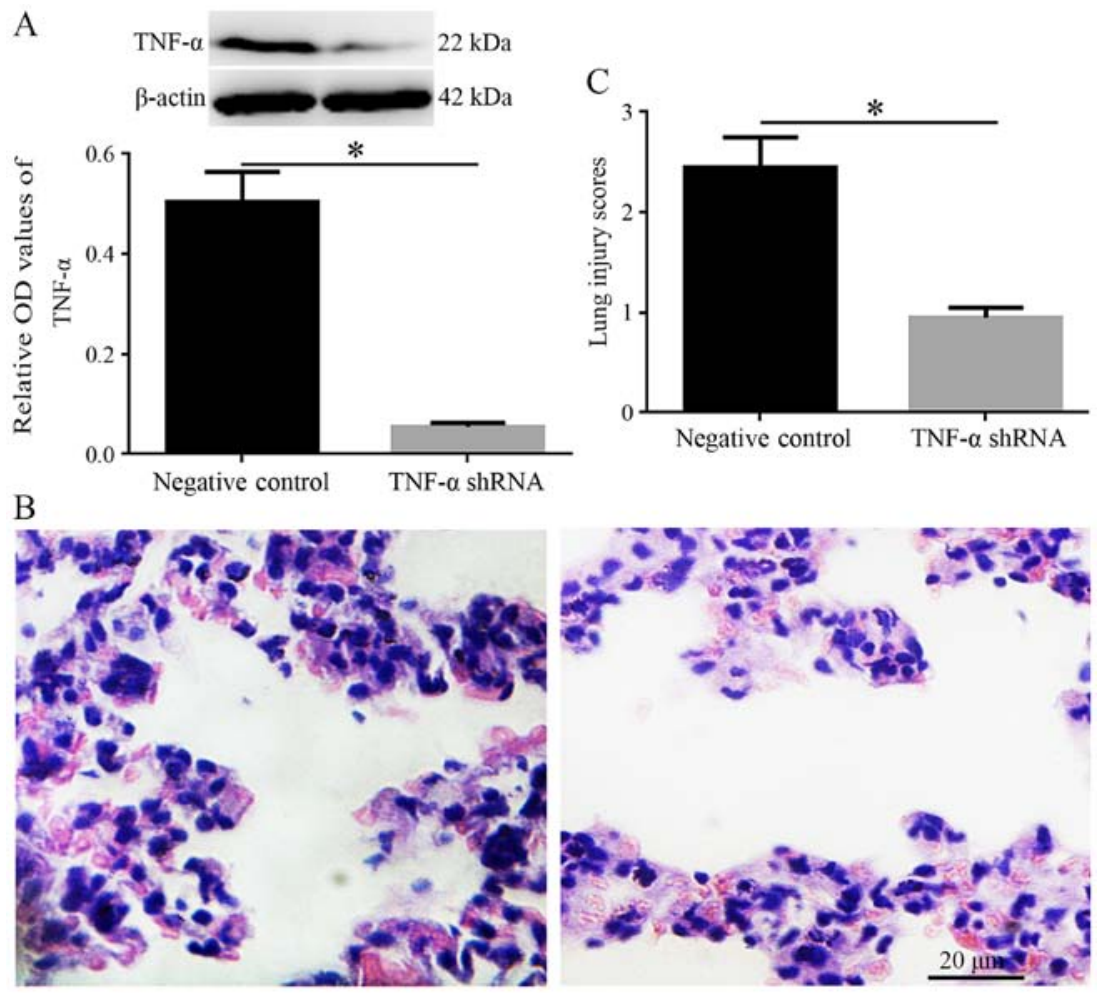

Figure 4. Alterations in lung injury following TNF- $\alpha$ interference. (A) Western blotting was used to detect TNF- $\alpha$ protein expression in lung tissues following TNF- $\alpha$ shRNA injection. Data are presented as the means \pm standard deviation $(\mathrm{n}=8)$. ${ }^{*} \mathrm{P}<0.05$ compared with the negative control group. (B) Hematoxylin and eosin staining of lung tissues from the negative control and TNF- $\alpha$ shRNA groups. The left image is the negative control group, and the right image is the TNF- $\alpha$ shRNA group. Scale bar, $20 \mu \mathrm{m}$. (C) Lung injury scores were improved in the TNF- $\alpha$ interference group $24 \mathrm{~h}$ post-reperfusion. Scores represent the average results of three blinded observers. Data are presented as the means \pm standard deviation $(n=6)$. ${ }^{*}<0.05$ compared with the negative control group. II/ $R$, intestinal ischemia and reperfusion; OD, optical density; shRNA, short hairpin RNA; TNF- $\alpha$, tumor necrosis factor- $\alpha$.

ting (Fig. 3B and C). Subsequently, the shRNA sequence was inserted into a plasmid to produce a recombinant vector, after which recombinant vectors containing TNF- $\alpha$ shRNA and mCherryFP were transfected into $293 \mathrm{~T} \alpha$ cells. IF detection confirmed that 293T $\alpha$ cell emitted red fluorescence, indicating successful transfection (Fig. 3D). These findings confirmed that lentivirus-mediated TNF- $\alpha$ interference was successful, and with the addition of lentivirus, TNF- $\alpha$ was significantly inhibited.

TNF- $\alpha$ knockdown ameliorates ALI following II/R. Following TNF- $\alpha$ inhibition, western blotting confirmed that the protein expression levels of TNF- $\alpha$ were significantly decreased in lung tissues $(\mathrm{P}<0.05$; Fig. 4A). Furthermore, H\&E staining indicated that inflammatory responses were improved, and lung injury scores were reduced $24 \mathrm{~h}$ after reperfusion in the TNF- $\alpha$ group compared with in the negative control group $(\mathrm{P}<0.05$; Fig. 4B and $\mathrm{C})$.

Knockdown of TNF- $\alpha$ upregulates the expression of IL-10. To determine the effects of TNF- $\alpha$ interference on the production of IL-10, the expression levels of IL-10 were detected in lung tissues. qPCR demonstrated that the mRNA expression levels of IL-10 were significantly increased in the TNF- $\alpha$ shRNA group compared with in the negative control group $(\mathrm{P}<0.05$; Fig. 5A). Furthermore, immunostaining of IL-10 was stronger in the TNF- $\alpha$ shRNA group than in the negative control group (Fig. 5B).

\section{Discussion}

The present study demonstrated that TNF- $\alpha$ knockdown may alleviate the inflammatory response associated with II/R-induced ALI by interfering with TNF- $\alpha$ expression and upregulating IL-10 in the lung tissues. These findings suggested that TNF- $\alpha$ RNA interference may be used as a strategy for the prevention or treatment of II/R-induced ALI in future clinical trials.

The present results indicated that II/R induced an acute inflammatory response in the lungs, in which adherence and infiltration of neutrophils was increased, and interstitial edema occurred; these observations were associated with worsened lung injury scores. These observations may significantly contribute to II/R-induced lung injury. Previous studies have reported that activated neutrophils are an important factor in tissue injury and serve a significant role in the progression of ALI (26-28). Therefore, the results of the present study demonstrated that lung injury was caused by II/R, thus confirming the model reliability.

The present study suggested that TNF- $\alpha$, either locally produced at the site of ischemia or generated directly from the lung tissue affected by II/R, had important effects on the lungs. The results indicated that TNF- $\alpha$ expression was upregulated in lung tissues, alongside ultrastructural alterations and lung injuries. In addition, the alterations in TNF- $\alpha$ expression levels differed with the time post-reperfusion. In the present study, the expression levels of TNF- $\alpha$ were increased 


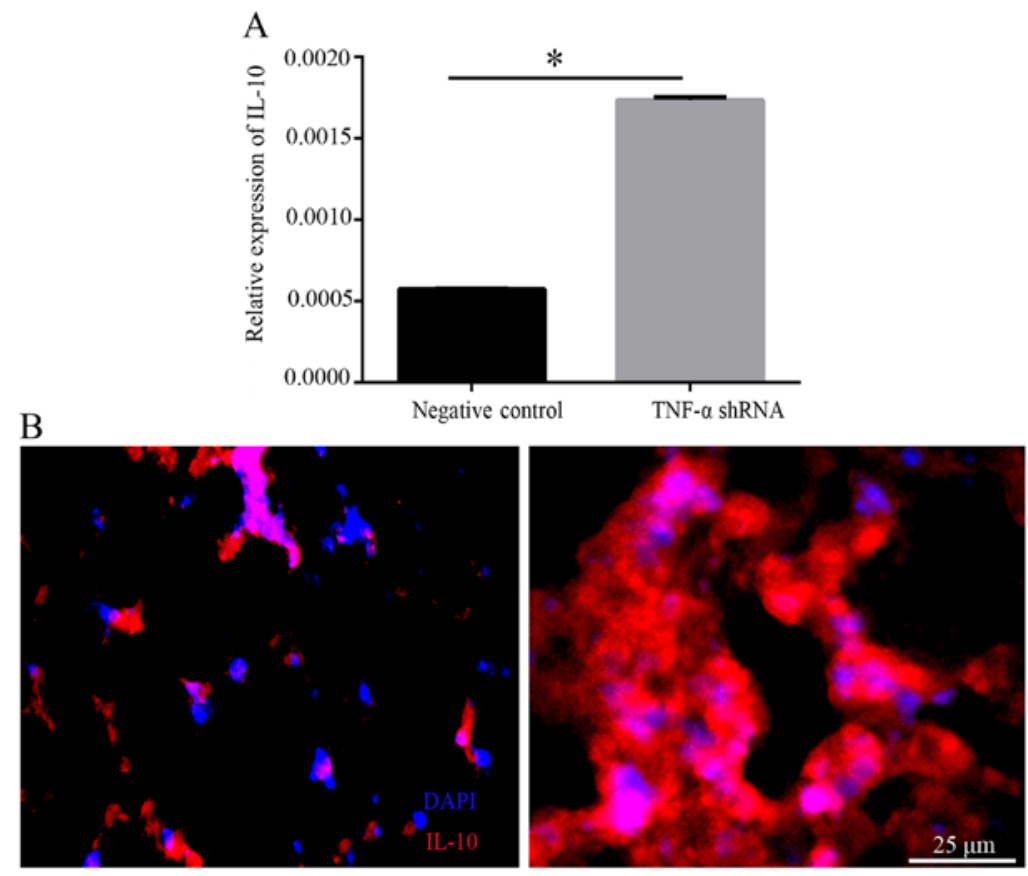

Figure 5. Expression of IL-10 following TNF- $\alpha$ interference. (A) A total of $24 \mathrm{~h}$ post-reperfusion, quantitative polymerase chain reaction indicated that the mRNA expression levels of IL-10 were significantly increased following TNF- $\alpha$ knockdown. Data are presented as the means \pm standard deviation $(n=8)$. ${ }^{*} \mathrm{P}<0.05$ compared with the negative control group. (B) Immunofluorescent staining of IL-10 in the lungs of the negative control and TNF- $\alpha$ shRNA groups. The left image is the negative control group, and the right image is the TNF- $\alpha$ shRNA group. Scale bar, $25 \mu \mathrm{m}$. IL-10, interleukin-10; shRNA, short hairpin RNA; TNF- $\alpha$, tumor necrosis factor- $\alpha$.

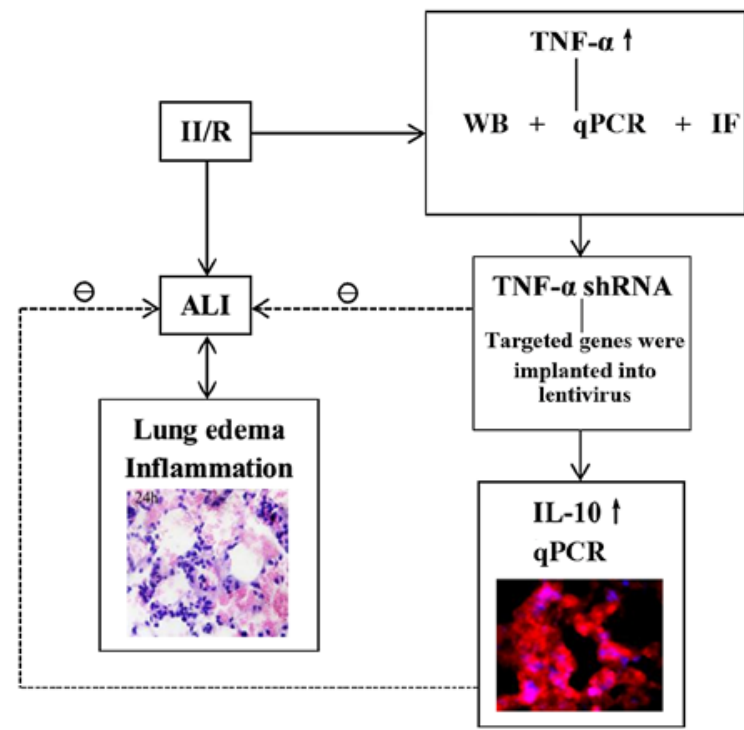

Figure 6. Diagram of the underlying mechanism by which TNF- $\alpha$ shRNA serves a protective role in a rat model of II/R-induced ALI. At various time points post-reperfusion, evidence of ALI was detected by hematoxylin and eosin staining. qPCR, WB and IF indicated that the expression levels of TNF- $\alpha$ were significantly increased in the lung tissues. TNF- $\alpha$ shRNA protected lungs from II/R-induced acute injury by upregulating IL-10 expression. The circles above the arrows indicate inhibition. ALI, acute lung injury; IF, immunofluorescence; II/R, intestinal ischemia and reperfusion; IL-10, interleukin-10; qPCR, quantitative polymerase chain reaction; shRNA, short hairpin RNA; TNF- $\alpha$, tumor necrosis factor- $\alpha$; WB, western blotting.

in the lung tissues of the II/R group after $8 \mathrm{~h}$ reperfusion and peaked $24 \mathrm{~h}$ post-reperfusion. A previous study provided evidence to suggest that in I/R injury, excessive elevation of proinflammatory cytokines is a major contributor in remote organ injury (12). The proinflammatory molecule, TNF- $\alpha$, can induce direct tissue damage and is also a potent activator of neutrophils $(29,30)$. In a previous study, Sorkine et al revealed that serum TNF concentration peaked 30 min after reperfusion, but returned to baseline values within $180 \mathrm{~min}$ (17). In addition, Narita et al reported that plasma TNF- $\alpha$ levels in an II/R group were increased $30 \mathrm{~min}$ after the start of ischemia, and fluctuated during I/R (30 min after intestinal reperfusion); however, $180 \mathrm{~min}$ after reperfusion, the plasma TNF levels were not significantly increased in the intestinal I/R rats compared with in the sham rats (12). Conversely, the present results indicated that the longer the duration of reperfusion, the higher the levels of TNF- $\alpha$, this may underlie the reason why more severe lung injury was detected 24 h post-reperfusion. These findings indicated that the mRNA expression levels of TNF- $\alpha$ in lung tissue may be more associated with the degree of lung injury compared with plasma levels prior to $24 \mathrm{~h}$ post-reperfusion.

The present study demonstrated that TNF- $\alpha$ lentiviral interference decreased the acute inflammatory response, lung injury and lung edema induced by II/R in rats, and it was indicated that its protective role may involve upregulation of IL-10. Until recently, siRNAs have been considered particularly specific $(31,32)$. However, there is growing evidence to suggest that the technique has limitations with regards to siRNA specificity and long-term effects $(14,20)$, whereas shRNAs maintain longer expression and were therefore used in the present study.

In previous studies, blockade of TNF- $\alpha$ has been reported to improve or prevent inflammation in animal models and in humans for the treatment of disease (33-36). In addition, it has been demonstrated that nanoparticle-mediated TNF- $\alpha$ knockdown in peritoneal macrophages may be used to reduce local and systemic inflammation, thereby presenting a novel 
therapeutic strategy for arthritis, psoriasis and other skin disorders $(22,37)$. Furthermore, potent RNAi against systemic TNF- $\alpha$ production provides a promising approach for the treatment of hepatic injury and other inflammatory diseases (38).

The treatment for II/R-induced ALI is currently limited. It has previously been reported that remote intestinal ischemic preconditioning may confer cytoprotection in critical organs, including the lungs, by attenuating the release of the proinflammatory cytokines TNF- $\alpha$ and IL-1 $(12,39)$. Furthermore, it has been revealed that applying hydrogen-rich saline, ELR-CXC chemokine inhibitors or heparin-binding EGF-like growth factor attenuates II/R-induced lung injury by inhibiting II/R injury-associated inflammatory events in clinical situations (40-42). However, few studies have focused on the protective effects of TNF- $\alpha$ knockdown, the possible mechanisms underlying II/R-induced ALI and the potential clinical application of TNF- $\alpha$ RNAi in patients with II/R-induced ALI. To the best of our knowledge, the present study is the first to demonstrate the protective effects of TNF- $\alpha$ RNAi on II/R-induced ALI via the upregulation of IL-10 expression (Fig. 6).

In conclusion, the present study demonstrated that TNF- $\alpha$ may be a major contributor in II/R-induced ALI, and TNF- $\alpha$ RNAi may alleviate the severity of ALI. Notably, TNF- $\alpha$ RNAi exerted a protective effect on II/R-induced ALI via upregulation of the anti-inflammatory cytokine IL-10. Based on these findings, TNF- $\alpha$ knockdown may be considered a novel therapeutic strategy for the treatment of II/R-induced ALI.

\section{Acknowledgements}

The authors would like to thank Dr Qing-Jie Xia (West China Hospital, Sichuan University, Chengdu, China) for suggestions on this study.

\section{Funding}

The present study was supported by a grant from the Key Natural Science Foundation of Yunnan (grant no. 2013FZ264).

\section{Availability of data and materials}

All data generated or analyzed during this study are included in this published article.

\section{Authors' contributions}

ZY, XRZ, THW and YHZ designed the project and were major contributors in writing and revising the manuscript. QZ and SLW participated in the production of recombinant lentiviral vector. LLX and PZ carried out the II/R model and lentivirus injection. QZ, BY and ZBZ carried out the histological analysis. QZ, SYF, ZY and XRZ carried out the qPCR, IF staining, and western blot analysis. ZY, XRZ, THW and ZYH analyzed the data. All authors read and approved the final manuscript.

\section{Ethics approval and consent to participate}

Animal care and all experimental protocols were approved by the Institutional Medical Experimental Animal Care Committee of Kunming Medical University (Kunming, China).

\section{Consent for publication}

Not applicable.

\section{Competing interests}

The authors declare that they have no competing interests.

\section{References}

1. Tadros T, Traber DL, Heggers JP and Herndon DN: Effects of interleukin-1alpha administration on intestinal ischemia and reperfusion injury, mucosal permeability, and bacterial translocation in burn and sepsis. Ann Surg 237: 101-109, 2003.

2. Tendler DA: Acute intestinal ischemia and infarction. Semin Gastrointest Dis 14: 66-76, 2003.

3. Higuchi S, Wu R, Zhou M, Marini CP, Ravikumar TS and Wang P: Gut hyperpermiability after ischemia and reperfusion: attenuation with adrenomedullin and its binding protein treatment. Int J Clin Exp Pathol 1: 409-418, 2008.

4. Harward TR, Brooks DL, Flynn TC and Seeger JM: Multiple organ dysfunction after mesenteric artery revascularization. J Vasc Surg 18: 459-467, 1993.

5. Cui T, Miksa M, Wu R, Komura H, Zhou M, Dong W, Wang Z, Higuchi S, Chaung W, Blau SA, et al: Milk fat globule epidermal growth factor 8 attenuates acute lung injury in mice after intestinal ischemia and reperfusion. Am J Respir Crit Care Med 181: 238-246, 2010.

6 . Bellingan GJ: The pulmonary physician in critical care $* 6$ : the pathogenesis of ALI/ARDS. Thorax 57: 540-546, 2002.

7. Souza DG, Vieira AT, Soares AC, Pinho V, Nicoli JR, Vieira LQ and Teixeira MM: The essential role of the intestinal microbiota in facilitating acute inflammatory responses. J Immunol 173: 4137-4146, 2004.

8. Tamion F, Richard V, Lyoumi S, Daveau M, Bonmarchand G, Leroy J, Thuillez C and Lebreton JP: Gut ischemia and mesenteric synthesis of inflammatory cytokines after hemorrhagic or endotoxic shock. Am J Physiol 273: G314-G321, 1997.

9. Roten R, Markert M, Feihl F, Schaller MD, Tagan MC and Perret C: Plasma levels of tumor necrosis factor in the adult respiratory distress syndrome. Am Rev Respir Dis 143: 590-592, 1991.

10. Ito K, Ozasa $\mathrm{H}$ and Horikawa S: Edaravone protects against lung injury induced by intestinal ischemia/reperfusion in rat. Free Radic Biol Med 38: 369-374, 2005.

11. Guzel A, Kanter M, Guzel A, Pergel A and Erboga M: Anti-inflammatory and antioxidant effects of infliximab on acute lung injury in a rat model of intestinal ischemia/reperfusion. J Mol Histol 43: 361-369, 2012.

12. Narita K, Kuwabara Y and Fujii Y: Lung injury after intestinal ischemia-reperfusion may be avoided by the reduced absorption of locally produced cytokines. Surg Today 34: 937-942, 2004.

13. Caty MG, Guice KS, Oldham KT, Remick DG and Kunkel SI: Evidence for tumor necrosis factor-induced pulmonary microvascular injury after intestinal ischemia-reperfusion injury. Ann Surg 212: 694-700, 1990.

14. Kim DH and Rossi JJ: Strategies for silencing human disease using RNA interference. Nat Rev Genet 8: 173-184, 2007.

15. Elbashir SM, Harborth J, Lendeckel W, Yalcin A, Weber K and Tuschl T: Duplexes of 21-nucleotide RNAs mediate RNA interference in cultured mammalian cells. Nature 411: 494-498, 2001.

16. Hall J: Unravelling the general properties of siRNAs: strength in numbers and lessons from the past. Nat Rev Genet 5: $552-557,2004$

17. Sorkine P, Setton A, Halpern P, Miller A, Rudick V, Marmor S, Klausner JM and Goldman G: Soluble tumor necrosis factor receptors reduce bowel ischemia-induced lung permeability and neutrophil sequestration. Crit Care Med 23: 1377-1381, 1995.

18. Artigas A, Bernard GR, Carlet J, Dreyfuss D, Gattinoni L, Hudson L, Lamy M, Marini JJ, Matthay MA, Pinsky MR, et al: The American-European Consensus Conference on ARDS, part 2: ventilatory, pharmacologic, supportive therapy, study design strategies, and issues related to recovery and remodeling. Acute respiratory distress syndrome. Am J Respir Crit Care Med 157: 1332-1347, 1998.

19. Bosher JM and Labouesse M: RNA interference: genetic wand and genetic watchdog. Nat Cell Biol 2: E31-E36, 2000. 
20. Younis A, Siddique MI, Kim CK and Lim KB: RNA interference (RNAi) induced gene silencing: a promising approach of Hi-Tech plant breeding. Int J Biol Sci 10: 1150-1158, 2014.

21. Liu R, Zhao W, Zhao Q, Liu SJ, Liu J, He M, Xu Y, Wang W, Liu W, $\mathrm{Xia}$ QJ, et al: Endoplasmic reticulum protein 29 protects cortical neurons from apoptosis and promoting corticospinal tract regeneration to improve neural behavior via caspase and Erk signal in rats with spinal cord transection. Mol Neurobiol 50: 1035-1048, 2014.

22. Howard KA, Paludan SR, Behlke MA, Besenbacher F, Deleuran B and Kjems J: Chitosan/siRNA nanoparticle-mediated TNF-alpha knockdown in peritoneal macrophages for anti-inflammatory treatment in a murine arthritis model. Mol Ther 17: 162-168, 2009.

23. Pei YH, Cai XM, Chen J, Sun BD, Sun ZR, Wang X and Qian XM: The role of $\mathrm{p} 38 \mathrm{MAPK}$ in acute paraquat-induced lung injury in rats. Inhal Toxicol 26: 880-884, 2014.

24. Kim K, Li Y, Jin G, Chong W, Liu B, Lu J, Lee K, Demoya M, Velmahos GC and Alam HB: Effect of valproic acid on acute lung injury in a rodent model of intestinal ischemia reperfusion. Resuscitation 83: 243-248, 2012

25. Livak KJ and Schmittgen TD: Analysis of relative gene expression data using real-time quantitative PCR and the 2(-Delta Delta C(T)) method. Methods 25: 402-408, 2001.

26. Sayan H, Ozacmak VH, Sen F, Cabuk M, Atik DY, Igdem AA and Ozacmak ID: Pharmacological preconditioning with erythropoietin reduces ischemia-reperfusion injury in the small intestine of rats. Life Sci 84: 364-371, 2009.

27. Sukhotnik I, Slijper N, Pollak Y, Chemodanov E, Shaoul R, Coran AG and Mogilner JG: Parenteral omega-3 fatty acids (Omegaven) modulate intestinal recovery after intestinal ischemia-reperfusion in a rat model. J Pediatr Surg 46: 1353-1360, 2011.

28. Grommes $\mathbf{J}$ and Soehnlein O: Contribution of neutrophils to acute lung injury. Mol Med 17: 293-307, 2011.

29. Zhao C, Sun J, Fang C and Tang F: 1,8-Cineol attenuates LPS-induced acute pulmonary inflammation in mice. Inflammation 37: 566-572, 2014.

30. Rinkema LE, Bemis KG and Fleisch JH: Production and antagonism of cutaneous vascular permeability in the guinea pig in response to histamine, leukotrienes and A23187. J Pharmaco Exp Ther 230: 550-557, 1984.

31. Fattal $\mathrm{E}$ and Bochot $\mathrm{A}$ : Ocular delivery of nucleic acids: antisense oligonucleotides, aptamers and siRNA. Adv Drug Deliv Rev 58 1203-1223, 2006.

32. Oshitari T, Brown D and Roy S: siRNA strategy against overexpression of extracellular matrix in diabetic retinopathy. Exp Eye Res 81: 32-37, 2005
33. Neurath MF, Fuss I, Pasparakis M, Alexopoulou L, Haralambous S, Meyer zum Büschenfelde KH, Strober W and Kollias G: Predominant pathogenic role of tumor necrosis factor in experimental colitis in mice. Eur J Immunol 27: 1743-1750, 1997.

34. Myers KJ, Murthy S, Flanigan A, Witchell DR, Butler M, Murray S, Siwkowski A, Goodfellow D, Madsen K and Baker B: Antisense oligonucleotide blockade of tumor necrosis factor- $\alpha$ in two murine models of colitis. J Pharmacol Exp Ther 304: 411-424, 2003.

35. Powrie F, Leach MW, Mauze S, Menon S, Caddle LB and Coffman RL: Inhibition of Th1 responses prevents inflammatory bowel disease in scid mice reconstituted with $\mathrm{CD} 45 \mathrm{RB}^{\text {hi }} \mathrm{CD}^{+}$ T cells. Immunity 1: 553-562, 1994.

36. Hartmann G, Bidlingmaier C, Siegmund B, Albrich S, Schulze J, Tschoep K, Eigler A, Lehr HA and Endres S: Specific type IV phosphodiesterase inhibitor rolipram mitigates experimental colitis in mice. J Pharmacol Exp Ther 292: 22-30, 2000.

37. Jakobsen M, Stenderup K, Rosada C, Moldt B, Kamp S, Dam TN, Jensen TG and Mikkelsen JG: Amelioration of psoriasis by anti-TNF-alpha RNAi in the xenograft transplantation model. Mol Ther 17: 1743-1753, 2009.

38. Yin L, Song Z, Qu Q, Kim KH, Zheng N, Yao C, Chaudhury I, Tang H, Gabrielson NP, Uckun FM, et al: Supramolecular self-assembled nanoparticles mediate oral delivery of therapeutic TNF- $\alpha$ siRNA against systemic inflammation. Angew Chem Int Ed Engl 52: 5757-5761, 2013.

39. Wang Z, Ji Y, Wang S, Wang R, Li Z, Kang A, Xu H, Shi M and Zhao M: Protective effect of intestinal ischemic preconditioning on ischemia reperfusion-caused lung injury in rats. Inflammation 38: 424-432, 2015.

40. Mao YF, Zheng XF, Cai JM, You XM, Deng XM, Zhang JH, Jiang L and Sun XJ: Hydrogen-rich saline reduces lung injury induced by intestinal ischemia/reperfusion in rats. Biochem Biophys Res Commun 381: 602-605, 2009.

41. Zhao X, Town JR, Yang A, Zhang X, Paur N, Sawicki G and Gordon JR: A novel ELR-CXC chemokine antagonist reduces intestinal ischemia reperfusion-induced mortality, and local and remote organ injury. J Surg Res 162: 264-273, 2010.

42. James IA, Chen CL, Huang G, Zhang HY, Velten $M$ and Besner GE: HB-EGF protects the lungs after intestinal ischemia/reperfusion injury. J Surg Res 163: 86-95, 2010.

This work is licensed under a Creative Commons Attribution-NonCommercial-NoDerivatives 4.0 International (CC BY-NC-ND 4.0) License. 